\title{
Factors for communication technologies selection within virtual software teams
}

\begin{abstract}
Virtual teams are established to during software development environment. Virtual team members are gradually engaged in globalized business environments across space, time and organizational boundaries with links ensured by information and communication technologies. A virtual team relies on communication, collaboration, and information exchange is the most important criteria in virtual teams operations and their efficiency directly influences team performance. The aim of this paper is to identify the factors of selecting and using of technologies within virtual teams communication to improve virtual team communication to enhance the virtual team performance. This researcher uses systematic literature review by Kitchenham to review existing literature on the issues and implementation of virtual team members. In this review 22 papers were analyzed to answer the research questions.
\end{abstract}

Keyword: Virtual teams; Communication; Performance 